\title{
Metal Additive Manufacturing Conference 2019, ASMET, Leoben, Austria
}

\author{
Gerhard Hackl and Bruno Hribernik
}

Leoben, Austria

Published online March 3, 2020

ASMET, the Austrian Society for Metallurgy and Materials, invited decision-makers, engineers, developers, industry experts, scientists, and students to the fourth Metal Additive Manufacturing Conference-MAMC 2019-with exclusive focus on the processing of metals.

The Metal Additive Manufacturing Conference took place from 25 to 27 November 2019 at Örebro Castle in Sweden. Örebro Castle is a medieval castle fortification in Örebro, Närke, Sweden, expanded during the reign of the royal family Vasa (House of Vasa) and finally rebuilt around the year1900.

The castle lies on an island in the river Svartån. The name of Örebro comes from the small stones, called "ör" in Swedish that a river transports. The second part of the word comes from the bridge ("bro") that was built over this ford. Important roads passed by this strategic place because from here one could control the traffic and the trade in the inner parts of Sweden. As a town, Örebro is 753 years old (it celebrated its 750-year anniversary in 2015). For many centuries, Örebro was one of the most important ports for the trade of iron from the Bergslagen.

The conference was the fourth in the series organised by the Austrian Society for Metallurgy and Metals (ASMET) and attracted over 200 participants from more than 20 countries.

The technical programme consisted of 62 oral presentations and identified the latest trends and innovative developments along the entire Additive Manufacturing (AM) process chain as well as numerous novel applications. The opportunities connected with such a dynamic technology raises interest in the materials and equipment industries, and an indication of the relevance of AM for the Swedish and global industry was given in the opening speech by County Director Anna Olofsson.

G. Hackl ( $₫)$

Leoben, Austria

Gerhard.Hackl@asmet.at
The morning of November 25 was dedicated to visits to $\mathrm{AMEXCl}$ and Lasertech LSH in Karlskoga, which is located approximately $35 \mathrm{~min}$ by bus from Örebro Castle.

$\mathrm{AMEXCl}$ was founded by ABB, Atlas Coco, Electrolux, Husqvarna Group, Höganäs, Saab, Scania, SKF, Stora Enso, and Wärtsiläand FAM on the principle of accelerating the industrial adoption of additive manufacturing and of helping to bring a new generation of innovative engineers and products to the market. AMEXCI has the in-house capacity of metal and polymer additive manufacturing and strives to be the best partner in applying its know-how throughout the product lifecycle in the field of additive manufacturing. Design for additive manufacturing, qualification and certification, and training and education are some of the focus areas at $\mathrm{AMEXCl}$.

Lasertech LSH AB started its operation in the year 2000 with the aim of becoming a leading supplier of laser welding services. The company is located in the middle of Sweden in the city of Karlskoga and currently has a total of 19 employees. Over the years the business has evolved and consists today of several other laser processing services, including laser marking, laser hardening, and laser cladding (LMD). Towards the end of 2018, the company invested in an all-new "3D-factory" with the aim of setting up a world class AM facility. The new factory started its operation in 2019.

The afternoon of November 27 was dedicated to a visit to Siemens Industrial Turbomachinery-3D printing plant in Finspång, which is located $80 \mathrm{~min}$ by bus from Örebro Castle.

Siemens is a global powerhouse focusing on the areas of electrification, automation and digitalization. In infrastructure and industry solutions the company plays a pioneering role.

Siemens in Finspong is a pioneer in the field of additive manufacturing and has invested in a complete workshop with all physical and digital support systems, filled with advanced 3D-printers for metal. The method applied is called Selective Laser Melting (SLM), one member of the pow- 
der bed fusion methods (PBF). More than 80 full time employees work with the development, execution, and quality assurance of the rapid prototyping of advanced gas turbine components, hybrid style repairs, spare parts on demand, and manufacturing activities. Siemens uses single and quadruple laser systems for the 3D-printing of mainly nickel base super-alloys for combustion systems and stainless steels. Siemens also develops proprietary special alloys for the hottest possible applications.

Nader Asnafi, Professor of Mechanical Engineering, arranged a two-day course in Design for Metal Additive Manufacturing in collaboration with some of the globally recognized lecturers, such as Jürgen Stampfl, Professor for Materials and Additive Manufacturing Technologies Vienna-University of Technology, Austria, and Professor Olaf Diegel, Head of the Creative Design and Additive Manufacturing Laboratory-The University of Auckland New Zealand. The course was held at Örebro University directly after the 4th Metal Additive Manufacturing Conference.

When compared to the MAMC conferences in 2014, 2016 and 2018 , there has been a significant progress regarding the materials, the understanding of the AM process, and the exploitation of new applications. For lightweight applications, such as those in the aerospace and space sectors and complex parts in gas turbines, there can be a clear argument for using metal AM. Topology optimisation, in combination with lattice structures, offers outstanding solutions for many advanced lightweight constructions.

The final decision between conventional manufacturing processes and AM remains a matter of economics for many applications. Yet, as recent presentations show, there is a significant increase of effort in all fields to promote AM for many interesting applications.

Details of the presentations can found in the conference proceedings, which can be ordered from ASMET (please contact lisa.loeschnauer@asmet.at). The 5th Metal Additive Manufacturing Conference-MAMC2020-is going to take place September 30-October 2, 2020, in Vienna, Austria.

Gerhard Hackl

Bruno Hribernik

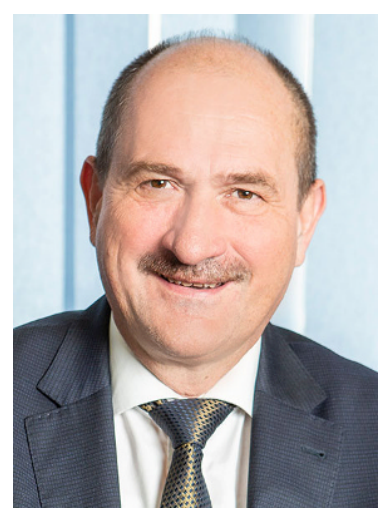

Gerhard Hackl

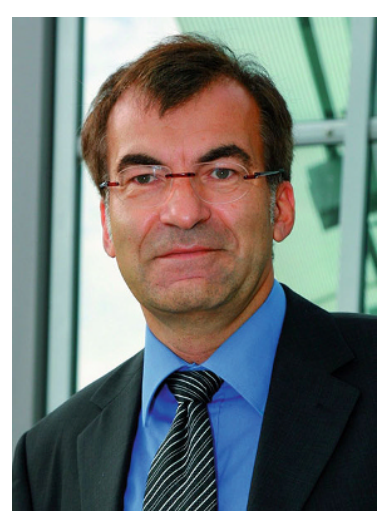

Bruno Hribernik

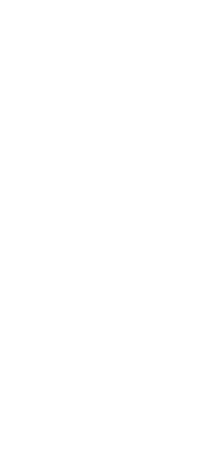

